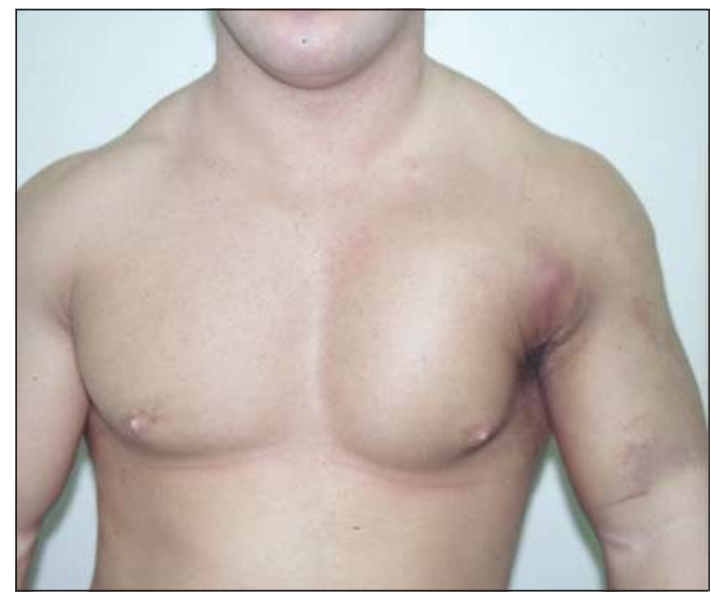

Loss of normal anterior axillary fold and contour of the pectoralis belly, along with substantial bruising around the axilla

fall into three main categories: traction techniques (Hippocrates, ${ }^{3}$ Stimson ${ }^{4}$ ) leverage techniques (Kocher, Milch $^{6}$ ), and scapular manipulation. ${ }^{7}$

Kocher's manoeuvre was originally described in $1870 .^{5}$ The affected arm is flexed at the elbow and adducted against the side of the body. The forearm is rotated externally and the upper arm lifted in a sagittal plane as far as possible and finally internally rotated. There have been many adjustments to this widely used technique, especially as the additional torque resulting from adduction and internal rotation have been associated with humeral shaft fractures in elderly people. ${ }^{89}$

To perform Kocher's manoeuvre the surgeon must abduct and externally rotate his own arm, this means the fibres of the sternocostal head of his pectoralis major are maximally stretched. If a patient is not well sedated or has not received adequate analgesia he or she is more likely forcefully to resist the reduction. This results in a sudden uncoordinated eccentric contraction of the surgeon's pectoralis major muscle, which in our case resulted in a pectoralis major rupture. If adequate sedation and pain relief are not possible, reduction under general anaesthetic may be necessary to minimise the risk of complications for both the patient and the doctor.

Competing interests: None declared.

Patissier P. Traite des maladies des artisans Paris. Paris, 1882:162-4.

2 Bak K, Cameron EA, Henderson IJP. Rupture of pectoralis major: a meta-analysis of 112 cases. Knee Surg Sports Traumatol Arthrosc. 2000; 8:113-9.

3 Mattick A, Wyatt JP. From Hippocrates to the Eskimo-a history of techniques usedto reduce anterior dislocation of the shoulder. J R Coll Surg Edinb 2000;45:312-6.

4 Stimson LA. An easy method of reducing dislocations of the shoulder and hip. Med Record 1900;356.

5 Kocher T. Eine neue Reductionsmethode für Schuletrverrenkung. Berliner Klin Wehnschr 1870;7:101-5.

6 Milch H. Treatment of dislocation of the shoulder. Surgery 1938;3:732-40.

7 McNamara RM. Reductions of anterior shoulder dislocations by scapular manipulation.Ann Emerg Med 1993;22:1140-4.

8 manipulation.Ann Emerg Med 1993;22:1140-4. Beattie TF, Steedman DJ, McGowan A, Robertson CE. A comparison of
Milch and Kocher techniques for the acute anterior dislocation of the shoulder. Injury 1986;17:349-52.

9 Riebal GD, McCabe JB. Anterior shoulder dislocation: a review of reduction techniques. Am J Emerg Med 1991;9:180-8.

\title{
Easy ways to resist change in medicine
}

\author{
Allen F Shaughnessy, David C Slawson
}

These time honoured techniques will help doctors resist the forces that prevail on them to change their ways of taking care of patients

Numerous forces have been imposed on physicians to make them change their practice behaviours. Under the guise of "quality improvement," managed care organisations, accrediting bodies, and the government are meddling in medicine. Even continuing medical education, previously a form of intellectual entertainment or a forum for much needed sleep, has refocused its efforts towards improving the care of patients (figure).

\section{Techniques to resist change}

Techniques are available, however, that will allow doctors to practise unimpeded by new information that should induce change. To avoid succumbing to both the inner and outer forces prompting change, we offer the following techniques and methods.

\section{Don't pay attention}

Get so busy with your practice that you do not have the time to read, attend meetings, understand your own practice, or observe the practice of colleagues. Forget about Stephen Covey's seventh habit of "sharpening the saw." Create your own habit of sawing harder and harder, with a dull saw.

\section{Attack the data}

When provided with new information that may require a change in practice:

- Firstly, diss the source. No one expects you really to believe information from sources outside your specialty or geographical area.

- Secondly, question the validity of the information. Every study or report contains some loophole in its

\section{Levels of belief}

- Class 0: Things I believe

- Class 0a: Things I believe despite the available data

- Class 1: Randomised controlled clinical trials that agree with what I believe

- Class 2: Other prospectively collected data

- Class 3: Expert opinion

- Class 4: Randomised controlled clinical trials that don't agree with what I believe

- Class 5: What you believe that I don’t 


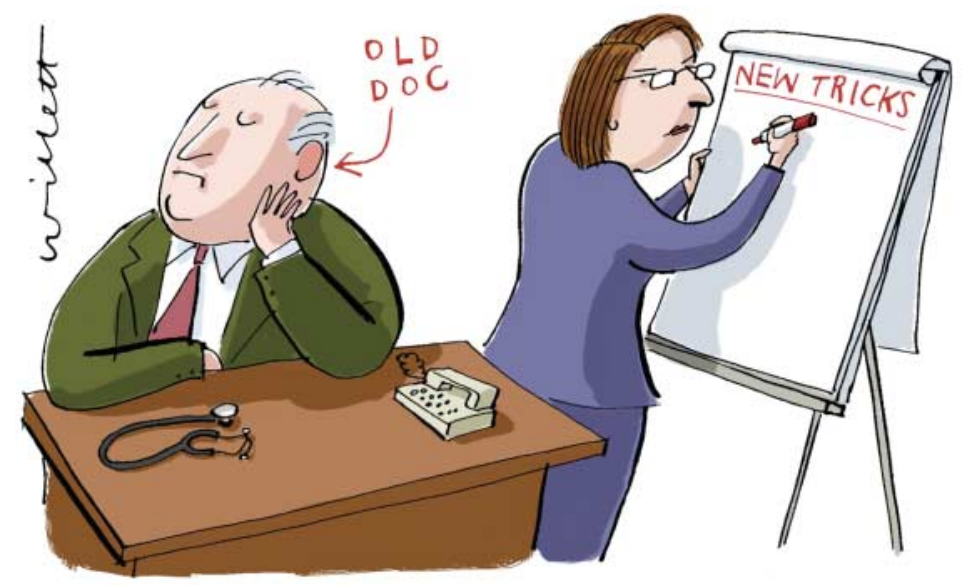

fabric, however small, that can be snagged and used to unravel the validity of the whole study. Use the common logical ploy that holds that if any aspect of the study is imperfect, the entire study results must be wrong.

- Thirdly, question the applicability to your patients. Studies are done "out there" and can't possibly reflect the unique nature of your practice. This technique is especially useful when data from large studies contradict our impressions gleaned from personal experience with a few patients.

\section{Maintain absolute confidence}

Remember all the smart professors you had and realise that everything you need to know to practise good medicine was taught in medical school. Instead of worrying about this newfangled "evidence based" medicine, stick with "belief based medicine" and organise your thoughts by using the criteria in the box. ${ }^{2}$

\section{Follow the pack}

Stay far back, waiting for all your colleagues to change before you (reluctantly) join them. Of course, if you practise skill \#1 correctly, you will never know what your colleagues are doing.

\section{Defer to experts}

Be sure not to make any independent decisions. An expert is always available somewhere to support your death grip on the status quo.

\section{Bring in the lawyers}

A good defence against change is to assert that you will get sued if you start doing something new or quit an old, favourite practice.

\section{Blame patients}

Claim that you'd like to practise differently but patients won't like it. Everyone will understand why you still give monthly injections of vitamin B-12 for anaemia and antibiotics for colds if you tell them your patients don't want you to stop.

\section{Show how much you've changed}

Point to all the new drugs you use as a result of information solely provided by pharmaceutical representatives. After all, it's more important to feel up to date than to actually be up to date.

\section{Pull rank}

When a case manager calls, a nurse or pharmacist makes a suggestion, or a patient brings in information they've downloaded, make sure to ignore it. Be sure to say, "When did you get your medical degree?"

\section{Simply refuse}

When presented by threatening information, say what was muttered after a presentation for continuing medical education: "I wouldn't believe this information even if it were true."

\section{Total control}

Using these time honoured techniques will allow you to practise with the assurance that little thinking will be required that might distract you from the matter in hand-taking care of patients as you see fit-and will keep you in total control without any nagging feelings that there might be a better way to practise.

Contributors: AFS wrote the first draft, which was then edited and expanded by DCS.

Competing interests: None declared.

Covey SR. Seven habits of highly effective people: powerful lessons in personal change. 1st ed. New York: Free Press, 1990

2 Bleck TP. Alternatives to evidence based medicine: different rating scale could be used. BMJ 2000;321:239.

\section{The doctor and his pheasant}

Most patients in rural Wales have absolute faith in their doctors, and vice versa. This true story, which happened long, long ago, is an example of such faith.

An elderly man had been ill for many months but was not confined to bed. He was very well looked after by his wife and daughter. On a Friday evening before Easter the man's wife telephoned the doctor but he was out. The receptionist took the message. It was a request for the doctor to leave a death certificate for the "old boy." The doctor signed the death certificate, and it was picked up that evening.
After Easter the doctor decided to visit the family. He was surprised to see his patient sitting in a chair outside the back door. What was the story behind this?

The man's wife explained: "On the night before Easter we really thought he was going to die. We didn't want to call you out over Easter-hence the request for a death certificate. He is now back to his usual self and quite happy. This morning he shot a pheasant and he is giving it to you in recognition of your excellent service."

John Hughes retired general practitioner, Aberystwyth SY23 $2 N F$ 